Revista Signos

2010 / 43

Número Especial

Monográfico $\mathrm{N}^{\circ} 1$

13-26

\title{
Forças centrípetas e forças centrífugas em editoriais*
}

\author{
Francisco Alves Filho \\ Universidade Federal do Piauí \\ Brasil
}

Resumo: Um dos aspectos relevantes apontados nas teorias de gênero é o fato de que os gêneros incorporam e põem em funcionamento duas forças genéricas (des)reguladoras, uma de caráter centrípeto, que responde pela estabilidade/integridade dos gêneros, e uma outra de feição centrífuga, a qual atua para possibilitar a versatilidade/ instabilidade. Contudo, as teorias ainda não esclarecerem suficientemente como se dá a dialética entre estas duas forças. Tendo em face tal problemática, o objetivo deste trabalho é investigar as correlações entre integridade e versatilidade genérica tomando como objeto de estudo exemplares de editoriais de jornal de empresas jornalísticas diferentes. Percebemos que o que é caracteristicamente estável neste gênero situa-se no seu funcionamento em cada jornal, ou seja, enquanto é bastante saliente a recorrência de funções comunicativas, de estilo, de estrutura composicional e de temas nos editoriais de um único jornal, o mesmo não ocorre quando se analisa editoriais de jornais diferenciados.

Palavras-Chave: Editorial de jornal, versatilidade genérica, integridade genérica.

* Este trabalho teve o apoio financeiro da FAPEPI/CNPq (processo $n^{\circ}$ 20203.0484/2008)
e da CAPES (Projeto PROCAD/NF N ${ }^{\circ} 21001014008 P$ ), instituições às quais expresso meu
agradecimento.

Recibido: 20-XI-2009

Aceptado: 24-V-2010
Correspondencia: Francisco Alves Filho (chicofilhoo@gmail.com). Departamento de Letras, Universidade Federal do Piauí, Campus Ministro Petrônio Portela, Bairro Ininga Teresina Pi Brasil, CEP 64049-550, Brasil. 


\section{Fuerzas centrípetas y fuerzas centrífugas en las editoriales}

Resumen: Uno de los aspectos de relieve señalado en las teorías de género es el hecho de que los géneros incorporan y hacen funcionar dos fuerzas genéricas y (des)regladoras, una de carácter centrípeto, que se encarga de la estabilidad/integridad de los géneros, y otra de rasgo centrífugo, la cual actúa a fin de que se dé la versatilidad/inestabilidad. Sin embargo, tales teorías todavía no aclaran completamente cómo se da la dialéctica entre ambas fuerzas. Delante de tal problemática, el objetivo de este trabajo es investigar las correlaciones entre integridad y versatilidad genérica teniendo como objeto de estudio ejemplares de editoriales de diarios de empresas periodíasticas distintas. Nos damos cuenta de que lo que es característicamente estable en este género se ubica en el funcionamiento de cada diario, o sea, mientras es bastante saliente la recurrencia de funciones comunicativas, de estilo, de estructura composicional y de temas en los editoriales de un único diario, lo mismo no sucede cuando se analisan editoriales de diferentes periódicos.

Palabras Clave: Editorial periodística, versatilidad genérica, integridad genérica.

\section{Centripetal and centrifugal forces in editorials}

Abstract: One of the relevant aspects in genre theory is the fact that genres incorporate and put into function two generic (dis)regulatory forces. One has a centripetal character, responsible for the genre stability/integrity. The other, centrifugal, acts to make versatility/instability possible. However, theories do not make clear the dialectics between such forces. Taking the above into account, this paper aims at investigating the correlations between generic integrity and versatility by analyzing editorials from different Brazilian journalistic enterprises. It can be noted that what is stable in such genre is related to the functioning of each newspaper; that is, while communicative functions, style, composition structure and theme are very recurrent in the editorial of a single newspaper, the same thing does not happen in analyzing different newspaper editorials.

Key Words: Newspaper editorial, generic versatility, generic integrity.

\section{INTRODUÇ̃̃̃O'}

Tendo em vista a necessidade de uma compreensão mais precisa do conceito de gênero e de seu comportamento em contextos reais, é objetivo deste artigo rediscutir o próprio conceito de gênero tomando por parâmetros o seu funcionamento em instituições particulares. Olhar para a linguagem tendo por instrumento de observação a noção de gêneros possibilita, entre outras coisas, compreender o funcionamento real da linguagem conforme praticada e concebida pelos próprios usuários da linguagem. Por esta razão, o estudo dos gêneros não deveria ter como foco a linguagem abstraída das situações ou formalizada teoricamente. 0 problema é que a rotulação dos gêneros realizada pelos próprios usuários da linguagem pode se apresentar enganadora na medida em que dá a entender uma classe universal e homogênea de textos. Tendo em vista 
a existência de uma contradição entre rotulação de gêneros e uso efetivo destes, objetivamos discutir os papéis desempenhados pela rotulação e pelos propósitos comunicativos na constituição de uma amostra de editoriais de jornais brasileiros.

\section{Forças centrípetas e forças centrífugas do gênero}

Várias vertentes teóricas dos estudos sobre gêneros do discurso das últimas quatro décadas, por percursos diferentes, apontam para o fato de que os gêneros são marcados por duas forças opostas e aparentemente contraditórias: uma força que regula, normatiza, estabiliza, generaliza, promove recorrência, a qual será chamada aqui de 'força centrípeta'; e outra que desestabiliza, relativiza, dinamiza, 'plasticiza', surpreende, aqui nomeada como 'força centrífuga'. Esta nomenclatura provém de Bakhtin (1988) e foi aplicada às forças da língua: em acordo com seu raciocínio, as forças centrípetas atuam com vistas a normatizar, unificar e tornar homogênea a língua, ao passo que as forças centrífugas atuam no sentido de estratificar e tornar heterogênea a língua. Estas duas forças podem ser compreendidas também como dois discursos que atuam sobre as línguas, o que faz com que os enunciados reais sejam o terreno onde estas forçam duelam. Rodrigues (2001) chegou a dizer, seguindo Bakhtin, que o gênero é uma das forças centrífugas responsável pela estratificação da língua, o que não deixa de ser pertinente, embora incompleto, pelo fato de que, como argumentaremos nas linhas que seguem, os gêneros também são uma das forças centrípetas, pois também regulam e normatizam.

Essa aparente contradição do gênero quanto a sua estabilidade e instabilidade foi discutida no clássico texto de Bakhtin (1979: 279-280), quanto ele afirmou que o gênero é "um dado tipo de enunciado, 'relativamente estável' do ponto de vista temático, composicional e estilístico" onde o 'estável' pode ser lido como componente da força centrípeta e o 'relativamente' como pertencendo à força centrífuga. Como é dito literalmente no texto, a relativa estabilidade refere-se ao tema, ao estilo e à composição, mas sabemos hoje que isso se aplica também a outras categorias genéricas, como propósito, autoria, leitor presumido: todos podem ser relativamente estáveis em dado gênero. Se observarmos exemplares diferentes de um mesmo gênero poderemos perceber como não há total estabilidade dos propósitos comunicativos, visto que novos propósitos podem ser acrescidos, alguns podem ser postos de lado ou pode oscilar a proeminência entre um propósito e outro. Embora a idéia da relativa estabilidade seja extremamente pertinente para explicar os gêneros, Bakhtin não explicou exatamente em quais aspectos estão localizados a estabilidade e a instabilidade ${ }^{2}$ e como seria possível mostrar a relação dinâmica entre os dois processos. 0 propósito deste texto é justamente tentar avançar neste sentido e matizar como atuam estas duas forças. Contudo, e o mais importante 
nesta perspectiva, é conceber um gênero em sua totalidade, como uma estrutura dinâmica equilibrando-se entre um polo centrífugo e um polo centrípeto.

Ao refletir sobre os gêneros literários, Bakhtin (1997: 121) novamente alude a este caráter duplo dos gêneros ao apontar para o fato de que tais gêneros ao mesmo tempo refletem as “tendências mais estáveis, 'perenes' da evolução da literatura”, conservando os 'elementos imorredouros', mas são 'atualizados ciclicamente'. No seu dizer 'o gênero sempre é e não é ao mesmo tempo'; 'sempre é novo e velho ao mesmo tempo'; 'renasce e se renova em cada nova etapa do desenvolvimento da literatura e em cada obra individual de um dado gênero'. A estabilidade é indiciada aqui pelos termos "sempre é" e "velho", ao passo que a instabilidade pode ser vista nos termos 'não é', 'novo', 'renova' e 'renasce'. Bakhtin também observa esta dualidade dos gêneros ao se aperceber da relação que eles mantêm com o passado e com o presente, ao enunciar que "o gênero vive do presente mas sempre recorda o seu passado, o seu começo” (Bakhtin, 1997: 121). 'Recordar o seu passado' resulta da atuação da força centrípeta, de conservação; já 'viver do presente' indicia que os gêneros sofrem a ação das forças centrífugas da atualidade, que os fazem pender e moldar-se para atender as necessidades dos que no momento presente os usam.

Também Bathia $(1993,1997)$, tendo em foco outras preocupações teórico-metodológicas, dá-se conta do que estamos chamando aqui de instabilidade estável ou da estabilidade instável ${ }^{3}$ dos gêneros. Ele formula a questão dizendo que os gêneros possuem ao mesmo tempo integridade genérica e tendência para a inovação. Bathia (1997) desenvolve sua reflexão diretamente sobre gêneros promocionais, situando-os nas esferas das empresas de mercado, as quais, por necessidades competitivas, induzem os membros experientes a explorar intensamente a dinamicidade dos gêneros. 0 construto dinâmico dos gêneros é vinculado a uma exploração tática por parte dos usuários experientes e expertos, uma vez que, em sua ótica, tal dinamicidade depende da manipulação operada por estes usuários. Como se vê, Bathia se dá conta da questão que envolve as forças centrípetas e centrífugas dos gêneros, localizando-as num universo bem particular, qual seja aquele das atividades promocionais e publicitárias no âmbito das empresas do mercado de negócios.

Outra autora a desenvolver uma concepção de gênero que pode ser compreendida como relacionada às forças centrífugas e centrípetas é Devitt (2004: 215), cujo argumento é favorável a uma teoria de gênero "dinâmica e paradoxal, englobando multiplicidade e variação assim como regularidade e estandardização, diacronia como também sincronia, indivíduo e sociedade”, [já que] "por definição, os gêneros são tanto forma como contexto, e eles tanto configuram como são configurados pelos contextos de situação, de cultura e de outros gêneros". Na mesma linha de raciocínio, defende também que "os gêneros servem como padrões de regularização e como 
capacitadores da variação e da criatividade" e que para "trabalharem como eles o fazem, eles devem manter a tensão entre essas aparentes dicotomias” (Devitt, 2004: 215). Em nossa leitura, diríamos que a variação genérica e a criatividade podes ser vistas como resultado da força centrífuga, ao passo que os padrões de regularização decorrem da força centrípeta. Há, ainda, o estudo de Berkenkotter e Huckin (1995: 6), os quais defendem que "os gêneros são sempre lugares de luta entre a estabilidade e a mudança. Eles são inerentemente dinâmicos [e] mutantes ao longo do tempo em resposta a necessidades sociocognitivas dos usuários individuais". Novamente presenciamos um ponto de vista que enxerga uma tensão entre duas forças atuando sobre os gêneros: a estabilidade (força centrípeta) e mudança (força centrífuga).

Creio não haver dúvidas quanto ao fato de que os gêneros são constituídos e regulados pelas forças que aqui estamos chamando de centrífuga e centrípeta, as quais, muito provavelmente, atuam simultaneamente e dialeticamente (como forças contrárias, mas interrelacionadas). 0 equilíbrio, às vezes precário, existente entre as duas forças, pode ser tomado como um dos indícios de que estamos diante de um gênero. Ou seja, ao montarmos um conjunto de textos pertencentes a um mesmo gênero observaremos que eles exibem ao mesmo tempo marcas e funcionamento recorrentes e não recorrentes, traços estáveis mas também traços instáveis. A rigor, se buscarmos apenas elementos recorrentes não conseguiremos identificar um gênero, dado que o conjunto total de textos de um gênero é caracteristicamente também não recorrente em relação a uma ou várias categorias genéricas. Daria para sustentar que o conjunto de textos daquilo que se convencionou como um gênero específico possui uma grande descontinuidade, embora isso não seja frequentemente percebido pelos usuários e se imagine que eles constituem uma classe homogênea e com continuidade entre seus exemplares empíricos. Mas esta percepção apenas ocorre porque os usuários cotidianamente lidam com sub-agrupamentos de um gênero situados em universos bem menores que a totalidade dos textos de um gênero. Por exemplo, um leitor de jornal normalmente lida com notícias produzidas em poucos jornais de uma mesma localidade; um cientista lida com artigos de sua área de atuação; uma secretária opera com ofícios de um conjuntos de empresas da mesma esfera. Isso dá a impressão de estabilidade e homogeneidade em cada usuário.

\section{0 nome convencional do gênero}

Um aspecto que se afigura como um fator extremamente relevante para os processos de identificação e reconhecimento de um gênero são as convenções ligadas ao nome do gênero. Um dos dados mais evidentes de um gênero particular é o fato de que eles possuem um nome convencionado (Marcushi, 2008), em alguns casos fortemente estável (como se dá com editorial 
de jornal), embora haja casos em que não há grande estabilidade dos nomes. (Um exemplo interessante é o que foi apontado por Swales (2007) para o gênero Declaração Pessoal ou Declaração de Princípios, o qual possui dois nomes concorrentes.) Ou seja, o nome do gênero resulta diretamente de um processo de categorização cuja força centrípeta é capaz de rotular uma enorme quantidade de textos como pertencendo a um único gênero. Não podemos esquecer que o gênero é um referente construído ou fabricado e que, por isso, sua relação com conjuntos de textos empíricos não decorre de uma relação especular ou empírica. 0 argumento de Mondada e Dubois (2003) de que a referenciação é um processo de construção discursiva de objetos de discurso parece adequada para discutir os rótulos que são aplicados aos gêneros. Ou seja, mais que uma classe empírica de textos, um gênero é um objeto de discurso rotulado com a função de categorizar uma classe de textos.

A estabilidade quanto ao modo de referir um gênero pode facilmente ser vista do ponto de vista diacrônico. Por exemplo, os nomes dos gêneros notícia, editorial, crônica e anúncio publicitário, para citar apenas alguns poucos, datam de mais de um século e permanecem os mesmos, embora os referentes empíricos por estes nomes designados sejam bastante diferentes entre si e tenham sofrido mudanças acentuadas durante este tempo, tanto do ponto de vista formal quanto funcional e contextual. Devitt (2004: 576) explica este fenômeno reportando-se às mudanças históricas das formas genéricas: "as formas podem mudar mas os rótulos genéricos permanecem os mesmos". Também do ponto de vista sincrônico, a estabilidade do processo categorizador dos nomes dos gêneros também é bastante evidente. Se compararmos conjuntos atuais de anúncios publicitários de produtos diferentes e focados em consumidores diferentes veremos que eles são extremamente diferentes entre si, embora sejam rotulados por um mesmo nome de gênero.

Tal dissonância entre o nome de um gênero e a integridade genérica de textos empíricos pertencentes a este gênero deve ser vista como um índice de que a existência de um nome único para um gênero não garante que estamos diante de conjuntos de textos que constituam uma classe minimamente homogênea ou estável quanto às características formais, funcionais e retóricas capazes de delimitar um gênero. Já discutimos em outro trabalho (Alves Filho, 2009), a hipótese de que a estabilidade dos gêneros (mesmo relativa) somente se sustenta quando o gênero é investigado tal como funciona numa instituição, num conjunto de instituições ou numa comunidade discursiva. Provindos de instituições ou comunidades discursivas diferentes, os exemplares de um gênero poderão não apresentar quase nenhum traço inteiramente estável, embora possam ser percebidos como se fossem estáveis. 


\section{Gênero como universal concreto}

Rojo (2005) e Rodrigues (2001), apoiando-se em Bakhtin, defendem a tese de que o gênero pode ser tomado como um universal concreto, embora não se detenham a explicar exatamente o que significa tal caráter universal. Rojo (2005: 194), em nota de rodapé, diz sumariamente que "os gêneros seriam os universais concretos a partir dos quais se materializam os textos/ enunciados", mas não desmembra em detalhes o conceito e suas implicações. De minha parte vejo algumas dificuldades em aceitar que um gênero possa ser tomado como universal por, pelo menos três razões. Primeiro, se os gêneros são essencialmente históricos, e se todo fenômeno histórico é concebido de modo heterogêneo e particular por comunidades e ideologias diferentes, como sustentar que os gêneros possam ser universais? Eles indubitavelmente são uma classe, mas uma classe particular e situada em culturas específicas. Segundo, os traços constitutivos dos gêneros (tema, estilo, composição, autoria) são sempre marcadamente situados e não universais. Terceiro, a relação indissociável do gênero com sua situação de produção e circulação também é marcadamente particular e situada, tendo em vista que as situações são particulares, embora sejam percebidas como recorrentes, como bem explicou Miller (1984). Já ao discutir a questão intercultural ligada aos gêneros, Marcuschi (2009) apresenta vários exemplos para mostrar como um mesmo gênero é valorado de maneira bem diferente entre povos diferentes, o que se constitui em mais um argumento contrário à tese da universalidade dos gêneros de discurso.

Talvez um dos poucos aspectos que possa ser considerado universal num gênero é o seu nome rotulador (desprezando o fato de que em línguas diferentes o nome possa significar algo particular, além dos casos de falta de consenso quanto ao nome). Em face de tal problemática, parece-me mais apropriado pensar que os gêneros nem são construtos universais nem únicos, mas construtos de nível intermediário situados em culturas, grupos sociais e instituições, sendo nestas instâncias onde é possível compreender seu funcionamento e sua caracterização. Ou seja, o valor genérico somente pode ser apreendido em estreita relação com as situações recorrentes nas quais são produzidos e compreendidos (correlação, aliás, grandemente consensual entre os teóricos de gêneros, inclusive os que falam dos universais, como Rojo (2005) e Rodrigues (2001)). 0 que queremos defender aqui é que a estabilidade é um traço do gênero como uma subclasse situada em esferas de atividades, comunidades discursivas ou instituições (embora, mesmo nesta concepção a estabilidade possa entrar em confronto com a instabilidade). Isso pode ser reforçado pelo fato de que a universalidade de um gênero é uma grande abstração teórica, mas não uma realidade manipulada pelos usuários. 


\section{A estabilidade e a instabilidade em editoriais de jornal}

0 gênero editorial pode ser compreendido, numa abordagem teórica grandemente generalizante, como um gênero da esfera jornalística cuja função principal é apresentar uma avaliação acerca de fatos recentes e considerados relevantes para certa comunidade de leitores, patrocinadores e produtores de informação. Melo (1994), por exemplo, aponta que a função do editorial é expressar a opinião da empresa jornalística acerca dos fatos recentes de uma sociedade. Dito desta maneira, esta concepção do gênero editorial aspira dar conta de um universal, e é isso que comumente é feito em manuais de jornalistas e mesmo em descrições de gêneros nos estudos realizados no campo da lingüística e do discurso. Entretanto, os bilhões de editoriais empíricos existentes na face da Terra não se acomodam confortavelmente a esta definição, visto que a variabilidade funcional, situacional e formal é muito grande.

De maneira bem geral, o editorial apresenta um funcionamento sócioaxiológico bastante heterogêneo, estando condicionado pelas relações de poder entre instituições jornalísticas, patrocinadores, Estado e leitores situados em culturas particulares. Sendo um gênero cuja função social é refletir valores e pontos de vista de setores influentes da sociedade, os editoriais servem para legitimar os valores dos grupos sociais dominantes. 0 estilo, o tema, o tempo de circulação e as funções comunicativas configuram uma rede enunciativa complexa através da qual os editoriais cumprem seu papel na vida social.

Van Dijk (1996), ao analisar um grande 'corpus' de editoriais de vários países, afirma que se deve esperar que nos editoriais apareçam, 'pelo menos', as seguintes categorias esquemáticas: sumário do evento; avaliação do evento - especialmente de ações e atores; conclusão pragmática (recomendação, conselho, advertência). Como veremos adiante, há muitos casos de editorias brasileiros em que não aparecem estas categorias, o que nos leva a defender que é bastante problemático caracterizar um gênero apenas (ou principalmente) em termos de estruturas esquemáticas.

Já a tese de Zavan (2009), investigando a tradição discursiva dos editorais em jornais no Estado do Ceará, no Brasil, serve para bem exemplificar a tese do dinamismo genérico entre forças centrípetas e forças centrífugas. Este estudo mostra claramente que tanto do ponto de vista diacrônico quanto sincrônico há variações de uso de vários recursos textuais e discursivos, mas, ao mesmo tempo, é possível apontar várias tendências. Ou seja, parece que a relativa estabilidade tanto ocorre no plano sincrônico quanto diacrônico. A análise feita por Zavan (2009) oferece sustentação para pensar na seguinte metáfora para explicar o funcionamento dos jornais: o jornal é uma instituição de aluguel, já que ele está a serviço de outras instituições que deles fazem uso. Isso fica bem claro nos jornais de escancarada prática panfletária do Ceará, 
mas seguramente de todo o Brasil e de outros países, a serviço direto de partidos políticos, de grupos familiares oligárquicos e de corporações financeiras.

A discussão sobre editorais aqui em andamento pode sugerir interessantes desdobramentos metodológicos. Se montarmos um conjunto de textos de um mesmo gênero pertencentes a instituições, culturas e comunidades discursivas diferentes chegaremos a um conjunto de tendências ou recorrências muito rarefeitas e dispersas. Por outro lado, ao montar um conjunto de textos de um mesmo gênero conforme praticados numa única instituição num mesmo período de tempo, será possível formular um conjunto de tendências ou recorrências bem mais recorrentes e homogêneos. Saussure nos chega quase automaticamente: o ponto de vista (e também de recorte) cria o objeto gênero.

Vejamos aqui o que ocorre com um conjunto de cinco editoriais de cinco jornais brasileiros diferentes. São dois jornais de circulação nacional (Folha de S. Paulo e O Estado de São Paulo, ambos da cidade de São Paulo) e três jornais de perfil regional (O Dia, de Teresina, O Jornal, de Maceió e Zero Hora, de Porto Alegre). Faremos uma análise comparativa observando os propósitos comunicativos (principais e secundários).

Tabela 1. Propósitos comunicativos de editoriais de jornais diferentes.

\begin{tabular}{|l|l|l|l|}
\hline \multicolumn{1}{|c|}{ Jornais } & \multicolumn{1}{|c|}{$\begin{array}{c}\text { Propósito } \\
\text { comunicativo principal }\end{array}$} & \multicolumn{1}{c|}{$\begin{array}{c}\text { Propósito comunicativo } \\
\text { secundário 1 }\end{array}$} & $\begin{array}{c}\text { Propósito comunicativo } \\
\text { secundário 2 }\end{array}$ \\
\hline $\begin{array}{l}\text { Folha de S. } \\
\text { Paulo }\end{array}$ & $\begin{array}{l}\text { Defender-se de } \\
\text { acusação }\end{array}$ & Criticar e desqualificar entidade & - \\
\hline $\begin{array}{l}\text { O Estado } \\
\text { de S. Paulo }\end{array}$ & $\begin{array}{l}\text { Fazer o relato de um } \\
\text { protesto }\end{array}$ & $\begin{array}{l}\text { Relatar a história da relação } \\
\text { entre uma instituição e sua } \\
\text { comunidade }\end{array}$ & $\begin{array}{l}\text { Posicionar-se diante de } \\
\text { uma controvérsia. }\end{array}$ \\
\hline O Dia & $\begin{array}{l}\text { Fazer um relato } \\
\text { biográfico }\end{array}$ & $\begin{array}{l}\text { Enaltecer as virtudes de um } \\
\text { homem público }\end{array}$ & - \\
\hline O jornal & $\begin{array}{l}\text { Divulgar o resultado } \\
\text { de uma pesquisa }\end{array}$ & Relatar análises dos resultados & $\begin{array}{l}\text { Relatar repercussões da } \\
\text { pesquisa }\end{array}$ \\
\hline Zero Hora & $\begin{array}{l}\text { Lamentar mudança } \\
\text { de comportamento do } \\
\text { Rio Grande do Sul }\end{array}$ & $\begin{array}{l}\text { Conclamar a sociedade para } \\
\text { recuperar comportamento } \\
\text { perdido }\end{array}$ & \multicolumn{1}{|c|}{} \\
\hline
\end{tabular}

Uma leitura da Tabela 1 evidencia diferenças significativas quanto aos propósitos comunicativos dos cinco editoriais. Quanto a este aspecto eles são grandemente diferentes, não comungando nenhum propósito, o que leva a pensar que o propósito comunicativo, por si só, pode ser alta- 
mente problemático se for tomado como critério único ou dominante para definir o pertencimento de um conjunto de textos a um dado gênero. Esse fato deve servir de alerta para que a definição e delimitação de um gênero leve em conta um conjunto variável, complementar e dinâmico de critérios, sem se concentrar em um ou dois somente.

A Tabela acima nos mostra também que a comparação entre exemplares de textos considerados de um mesmo gênero, mas pertencentes a instituições diversas, indica que eles são acentuadamente diferentes entre si. Entretanto, quando comparamos exemplares considerados de um mesmo gênero e pertencentes a uma mesma instituição percebemos uma grande homogeneidade quanto a propósitos comunicativos, estilo, tema e composição. Ou seja, a (relativa) estabilidade de um gênero ocorre num recorte menor do que o do gênero como um todo, mas numa instituição, comunidade discursiva ou lugar geográfico. Por esta razão, o nome de um gênero precisa ser visto com cautela pelo fato de ele rotular uma classe de textos extremamente heterogênea. Por outro lado, não deixa de ser curioso o fato de que classes de textos tão heterogêneas quanto a propósitos, temas, estilos e composição sejam tão facilmente reconhecidas como constituindo uma única classe. E, em contrapartida, provoca curiosidade o fato de sub-classes bem mais estáveis que a classe geral do gênero não possuírem rótulos que as identifiquem.

Observemos agora os dois editoriais reproduzidos abaixo, o primeiro publicado em Maceió, no estado de Alagoas, na Região Nordeste do Brasil e o segundo publicado em Teresina, também na Região Nordeste do Brasil.

\section{Editorial 1 Emergentes}

O Instituto de Pesquisa Econômica Aplicada (IPEA) divulgou ontem estudo segundo o qual 13,8 milhões de brasileiros subiram de faixa social entre 2001 e 2007. Os números confirmam a Pesquisa Nacional por Amostra de Domicílios de 2007 (Pnad 2007), divulgada na semana passada, e mostram que $74 \%$ ou 10,2 milhões, saíram da classe de baixa renda e 3,6 milhões de pessoas passaram da classe intermediária para a classe de renda mais alta.

Analistas atribuem a migração das pessoas de baixa renda ao crescimento da economia e aos programas de transferência de renda. Já o caso dos emergentes da classe intermediária é atribuído ao crescimento do mercado de trabalho, que teria proporcionado a inserção da mão-de-obra no mercado formal e de forma duradoura.

Apesar dos números favoráveis, especialistas alertam que o crescimento econômico é insuficiente do ponto de vista da redução das desigualdades regionais. Ou seja, os emergentes da classe de baixa renda têm baixa escolaridade e concentram-se nos estados do Norte e do Nordeste. A avaliação causou inquietação no Planalto. Ontem, o presidente 
Lula afirmou que vai convocar os governadores das duas regiões a tomar atitudes "mais ousadas" para reduzir as desigualdades.

O presidente Lula citou problemas históricos das duas regiões, como a falta de saneamento, a coleta inadequada do lixo e o analfabetismo como os entraves a combater prioritariamente. Ele voltou a defender a aplicação de recursos da exploração das novas descobertas do setor petrolífero em políticas sociais. 0 presidente sinalizou que o governo federal está interessado em reduzir as distâncias entre o Sul/Sudeste e o Norte/Nordeste. Cabe aos estados definir o que, dentre suas dificuldades, deve ser tratado como prioridade. $\mathrm{E}$ levar a Brasília não apenas a conta de quanto seria necessário para salvar o Estado, mas programas eficientes de gestão (0 Jornal, Maceió, 23 de setembro de 2008, p. A2).

\section{Editorial 1 \\ 0 exemplo de chaves}

A morte do monsenhor Joaquim Chaves, ocorrida ontem, é o fim biológico de um dos mais importantes intelectuais do Piauí, cuja formação humanística fez um clérigo respeitado, um dedicado estudioso dos costumes e da História, um professor admirado e um homem de aura de santo, cuja fé e as virtudes sempre foram alvo de generalizada admiração.

Com poucos, ele seguiu um modelo católico da busca da santidade, que não significa necessariamente operar milagres, mas ter atos bons e justos, construir e disseminar conhecimento. Também foi um homem humilde cultuando essa qualidade tão incomum num mundo dominado pela vaidade, presente mesmo em instituições não-seculares.

Chaves foi professor e guia de umas pelo menos três gerações e reportou uma sociedade inteira, olhando-a pelo viés do passado, dando-lhes meios para se conhecer melhor, ao produzir seus textos sobre a História do Piauí, peças fundamentais para a compreensão de quem somos e para onde caminhamos. Cumpriu com rigor uma missão que o faz grandioso.

Historiador responsável por obras de fundamental importância para o Piauí, Chaves foi, entretanto, vítima da falta de memória de boa parte das pessoas. Para quem tem menos de 40 anos e não freqüenta os círculos intelectuais e acadêmicos, monsenhor Chaves é o nome de uma Fundação de Cultura do município de Teresina, ou menos que isso. Uma injustiça muito própria destes tempos contemporâneos em que tudo se dissolve no ar com grande facilidade.

A figura aparentemente frágil de Chaves escondia um gigante da virtude e do conhecimento. Foi virtuoso não somente pelo sacerdócio clerical, mas em grande parte pelo amor que dedicou ao seu mister no magistério, como professor e diretor do Colégio Diocesano. Gigante com sua vasta historiografia e ainda mais com uma obra prática: as torres da Igreja Matriz de Nossa Senhora do Amparo, por muito tempo a mais elevada edificação da cidade de Teresina, cuja beleza arquitetônica lhes confere status de símbolo da cidade. 
Este homem santo agora não está entre nós, mas seu exemplo haverá de perdurar por muitos anos, seguramente por gerações inteiras, ainda que restrito aos círculos acadêmicos, porque sua obra está assentada sobre os pilares da virtude e do conhecimento científico, que são indestrutíveis, tal e qual a fé que ele professava. Sua grande bondade, sua dedicação à fé, à Igreja e à academia o acompanham para o túmulo, mas nos servem como guias para mantê-lo vivo como um símbolo da cidade de Teresina e do Estado do Piauí (Editorial do Jornal Meio Norte 09/05/07).

0 que poderíamos dizer que há de comum e de diferente entre os dois textos acima? Os propósitos comunicativos são claramente diferentes: o primeiro visa divulgar os resultados, as avaliações e as repercussões de uma pesquisa, ao passo que o segundo objetiva fazer um relato biográfico de um homem público enaltecendo suas virtudes e qualidades. No primeiro caso não há uma tomada de posição por parte da empresa jornalística, a qual apenas relata opiniões de outros setores da sociedade, enquanto no segundo exemplar a empresa jornalística claramente assume uma posição ao realizar uma avaliação extremamente positiva de um homem público recentemente falecido. Dois aspectos considerados por muitos autores como decisivos para determinar o pertencimento de um texto a um gênero, o propósito comunicativo (Swales, 1990) e o acabamento do enunciado (Bakhtin, 1979) não são aqui capazes de promover tal 'enquadramento' a um gênero. Mas por que será que ainda assim, se aceita que os dois exemplares de texto, tão diferentes entre si, pertencem ao mesmo gênero? Neste contexto, trata-se de uma pergunta de difícil resolução, cabendo-nos apenas levantar algumas hipóteses. Uma delas refere-se à convenção (até certo ponto arbitrária) genérica. Ou seja, o fato de o texto ter sido publicado na seção do jornal destinada a editorial e de o editor ter enunciado que ali se trata de um editorial parece ter uma força muito grande para indicar o pertencimento genérico, a despeito de diferenças entre características retóricas, funcionais e formais dos textos. Outra hipótese pode advir do fato de haver uma grande estabilidade quanto às características retóricas, funcionais e formais conforme praticadas em cada instituição, embora tais características divirjam em relação a outras instituições.

Por esta razão é que quando montamos um conjunto de editoriais pertencentes a uma mesma instituição jornalística chegaremos a resultados bem diferentes quanto à estabilidade do gênero do que chegaríamos se agrupássemos editoriais de instituições diferentes. Em cada instituição jornalística haverá uma grande estabilidade do gênero quanto a propósitos comunicativos, estilo e composição, embora ainda haja variação, mas num grau bem menor do que ocorre naquilo que se supõe ser a universalidade do gênero. É provável que o leitor assíduo de certo jornal consiga reconhecer a que gênero pertence um conjunto de textos deste jornal, mesmo se as marcas convencionais do gênero tiverem sido alijadas dos exemplares. Mas talvez não consiga identificar o pertencimento genérico de um conjunto de textos de um jornal que não the é familiar. 


\section{CONSIDERAÇÕES FINAIS}

O conceito de gênero é de uma natureza grandemente complexa porque os textos podem se agrupar em classes com base em mais de um critério. Além do mais, podemos deduzir que o nome que rotula um gênero pode mais refratar do que refletir o conjunto de textos empíricos que é tido como fazendo parte deste gênero, ou seja, o nome do gênero nos induz a pensar que as classes de textos são muito mais homogêneas do que o que de fato elas são. No geral, não se dispõe de rótulos para nomear conjuntos de textos que funcionam com bastante regularidade em certas instituições ou culturas disciplinares. Por outro lado, as rotulações disponíveis e consagradas historicamente talvez constituam-se como um modo sócio-cognitivo para se lidar com a complexidade e heterogeneidade das classes de textos, já que a rotulação destas classes facilita o trabalho de localização, identificação e modos de recepção dos textos. A observação dos editoriais aqui realizada indica que se trata de um gênero que, do ponto de vista de cada instituição jornalística isolada, é bastante estável e homogêneo, sendo mais influenciado pelas forças centrípetas, ao passo que quando se confronta instituições diferentes, ele se afigura com um grau acentuado de instabilidade, sendo mais influenciado pelas forças centrífugas. Em suma, ao passo que o nome rotulador do gênero funciona como uma força centrípeta, os propósitos comunicativos atuam como forças centrífugas e o editorial enquanto gênero equilibra-se entre estas duas forças e mantém-se vivo na sociedade.

\section{REFERÊNCIAS BIBLIOGRÁFICAS}

Alves Filho, F. (2009). Referenciação e gêneros do discurso: O que um tem a ver com o outro? Palestra apresentada no II CIELLA, Congresso Internacional de Estudos Lingüísticos e Literários da Amazônia, UFPA: Belém.

Devitt, A. (2004). Writing genres. Carbondale: Southern Illinois University Press.

Bakhtin, M. (1979[1953]) Os gêneros do discurso. Estética da criação verbal, 279-287.

Bakhtin, M. (1997). Problemas da poética de Dostoiévski. Rio de Janeiro: Forense Universitária.

Bakhtin, M. (1998 [1975]). Questão de literatura e de estética: a teoria do romance. São Paulo: Unesp/Hucitec.

Bathia, V. (1993). Analysing genre: Language use in professional settings. New York: Longman.

Bathia, V. (1997). Genre analysys today. Revue belge de philology e d'historie, 75(3), 629652. 
Melo, J. M. (1994). A opinião no jornalismo brasileiro. Petrópolis: Vozes.

Miller, C. (1984). Genre as social action. Quarterly Journal of Speech, 70, 151-167.

Mondada, L. \& Dubois, D. (2003). Construção dos objetos de discurso e categorização: Uma abordagem dos processos de referenciação. Em M. M. Cavalcante, B. B. Rodrigues \& A. Ciulla (Eds.), Referenciação (pp. 17-52). São Paulo: Contexto.

Rodrigues, R. H. (2001). A constituição e o funcionamento do gênero jornalístico artigo: Cronotopo e dialogismo. Tese de doutorado, LAEL/PUC-SP, São Paulo, Brasil.

Rojo, R. (2005). Gêneros do discurso e gêneros textuais: Questões teóricas e aplicadas. Em J. L. Meurer, A. Bonini \& D. Motta-Roth (Eds.), Gêneros: Teorias, métodos, debates (pp. 184-207). São Paulo: Parábola Editorial.

Swales, J. (1990). Genre analysis: English in academic and research settings. Cambridge: Cambridge UP.

Swales, J. (2007) Worlds of genre-metaphors of genre. Anais do IV Simposio Internacional de Estudos de Generos Textuais, Tubarão (SC). Disponível em: www3.unisul.br/paginas/ ensino/pos/linguagem/siget/index.htm

Zavan, A. (2009). Por uma abordagem diacrônica dos gêneros do discurso à luz da concepção de tradição discursiva: Um estudo com editoriais de jornais. Tese de doutorado, Universidade Federal do Ceará, Fortaleza, Brasil.

\section{NOTAS}

1 Este artigo é uma versão desenvolvida e ampliada do trabalho 'Integridade genérica versus versatilidade no editorial de jornal', apresentado no V SIGET, em Caxias do Sul, Brasil, em agosto de 2009.

2 Ao pensar sobre este aspecto vem à mente o fato de que a língua passa por um funcionamento parecido, dado que lhe é característico possuir um equilíbrio precário. Toda língua é ao mesmo tempo estável e instável; não fosse estável, dificilmente os falantes conseguiriam intercomunicar-se e compreenderem-se mutuamente; não fosse instável, não se adaptaria tão facilmente a novos contextos e novas significações.

3 Além de (ou mais do que) um jogo de palavras, optar por rotular este fenômeno por instabilidade estável ou estabilidade estável pode indicar o que se considera como mais dominante ou determinante. Falar de instabilidade estável realça o caráter instável como central e o estável como incidental (e vice-versa no caso do termo estabilidade instável). 